\title{
Mortality Risk in Necrotizing Fasciitis: National Prevalence, Trend, and Burden
}

\author{
Zaid Al-Qurayshi, ${ }^{1}$ Ronald L. Nichols, ${ }^{2}$ Mary T. Killackey, ${ }^{2}$ and Emad Kandil ${ }^{2}$
}

\begin{abstract}
Background: Necrotizing fasciitis (NF) is a fulminant, life-threating infection of fascia and subcutaneous tissue. Because of the low incidence, previous studies were statistically underpowered to assess factors associated with the risk of mortality. The aim of this study is to identify the risk factors associated with mortality in this select group of patients.

Methods: A retrospective cross-sectional study was performed utilizing the Nationwide Readmissions Database, 2010-2014. The database captures 56.6\% of all U.S. annual hospitalizations. Study population included inpatients admitted emergently with NF.

Results: A total of 4,178 cases were included, of which 2,061(48.9\%) patients had a history of diabetes mellitus (DM). The most common presentation was septicemia (39.5\%) and 9.2\% were admitted initially as cellulitis/ abscess. Overall mortality risk was $12.6 \%$ with no substantial change in the annual trend. Mortality in patients with diabetes was substantially lower $(8.5 \%$ vs. $16.5 \%$, odds ratio [OR]: $0.44,95 \%$ confidence interval $[\mathrm{CI}]=$ $[0.34,0.56], \mathrm{p}<0.001)$. Factors associated with a higher mortality risk included: older age, chronic liver diseases, disseminated intravascular coagulopathy, septic shock, pulmonary complications, acute renal failure, and not undergoing surgical intervention $(\mathrm{p}<0.05$ each). Patients who did not undergo surgical debridement were more likely to be $\geq 65$ years of age and have multiple comorbidities. Hyperbaric oxygen therapy and intravenous immunoglobulin were used in $1.3 \%$ and $0.3 \%$ of the sample, respectively, with no reported use among patients who died.

Conclusions: This study provides a new and updated perspective on the prevalence, trend, and outcomes of NF in the United States. Necrotizing fasciitis is associated with septicemia and lack of surgical intervention is associated with a higher mortality.
\end{abstract}

Keywords: necrotizing fasciitis; diabetes; prevalence; outcome; mortality risk; length of stay

$\mathbf{N}$ ECROTIZING FASCIITIS (NF) is a rare, fulminant, and lifethreating infection of fascia and subcutaneous tissue [1-4]. The incidence rate based on insurance claims data is 4 per 100,000 person-years [5]. The causative pathogens are evidenced to be changing over time, infection is typically polymicrobial, however, monomicrobial infection with $\beta$ hemolytic streptococci and methicillin-resistant Staphylococcus aureus (MRSA) have increasingly been reported $[1,2,4]$. Infection usually develops after an inciting event such as perirectal infection, trauma, intravenous drug abuse, chronic diabetic ulcerations, and surgical site infections [4,6].
Early identification and intervention are paramount for survival of patients presenting with NF [1]. Treatment often requires multiple and extensive surgical debridement, prolonged polymicrobial antibiotic coverage, and systematic support to prevent vital organs failure [1,4].

Because of the low incidence, previous investigations lacked reproducibility, and most studies were statistically underpowered to assess factors associated with the risk of mortality $[1,2]$. The aim of this study is to use nationally representative data to examine the clinical and demographic profile of patients admitted with NF and the risk of their mortality.

\footnotetext{
${ }^{1}$ Department of Otolaryngology-Head and Neck Surgery, University of Iowa Hospitals and Clinics, Iowa City, Iowa, USA.

${ }^{2}$ Department of Surgery, Tulane University School of Medicine, New Orleans, Louisiana, USA.
} 


\section{Patients and Methods}

This study is a retrospective cross-sectional analysis using the Nationwide Readmissions Database (NRD) for the years 2010-2014. The NRD is part of the Healthcare Cost and Utilization Project (HCUP), sponsored by the Agency for Healthcare Research and Quality. The NRD is a unique and powerful database designed to support various types of analyses of national re-admission rates for all payers and the uninsured. The database includes discharge data from 27 geographically dispersed states, accounting for $57.8 \%$ of the total U.S. resident population and $56.6 \%$ of all U.S. hospitalizations. Additionally, the database allows for weighted analysis that has been utilized in this project to provide a better estimation of national outcomes. The NRD tracks patient across the sampled hospitals within a calendar year for any re-admission. This database addresses a large gap in health care data, namely the lack of nationally representative information on hospital re-admissions for all ages. The NRD consists of publicly available de-identified data that is exempt from purview of the Institutional Review Board [7].

The NRD contains records of diagnoses and procedures developed during admission using the International Classification of Disease, 9th Revision (ICD-9). The database utilizes Clinical Classification Software and Elixhauser Comorbidity Software to categorize ICD-9 codes into broader clinical groups. Categorization generated by those software programs were used in this study to define the study parameters unless otherwise specified. Further information regarding the categorization scheme is available on the HCUP website [7].

The first objective of the study is to examine the clinical and demographic profile of patients who presented emergently with NF. The second objective of the study is to identify factors associated with the risk of mortality.

The study population included patients who were admitted emergently with NF. The NRD reports the principal diagnosis of admission. In certain cases, patients presented with compounded clinical picture and NF might be part of the presentation such as in trauma. This study included all patients with either NF as the principal diagnosis or a secondary diagnosis as illustrated in Figure 1. Patient with NF were identified by surveying the database for the ICD-9 code: 728.86. The code is limited because it does not include the site of infection, nonetheless, it has been previously used with good validity by other studies that reported NF $[2,5,8]$.

The included patients were followed for 30 days for readmission. The study sample was divided into two groups based on the presences of history of diabetes mellitus. Necrotizing fasciitis in patients with diabetes has been demonstrated to be distinctly different from that in patients without diabetes [2]. For this reason, we examined the difference in presentation and outcomes between both groups and assessed the mortality risk in each group separately. All records were

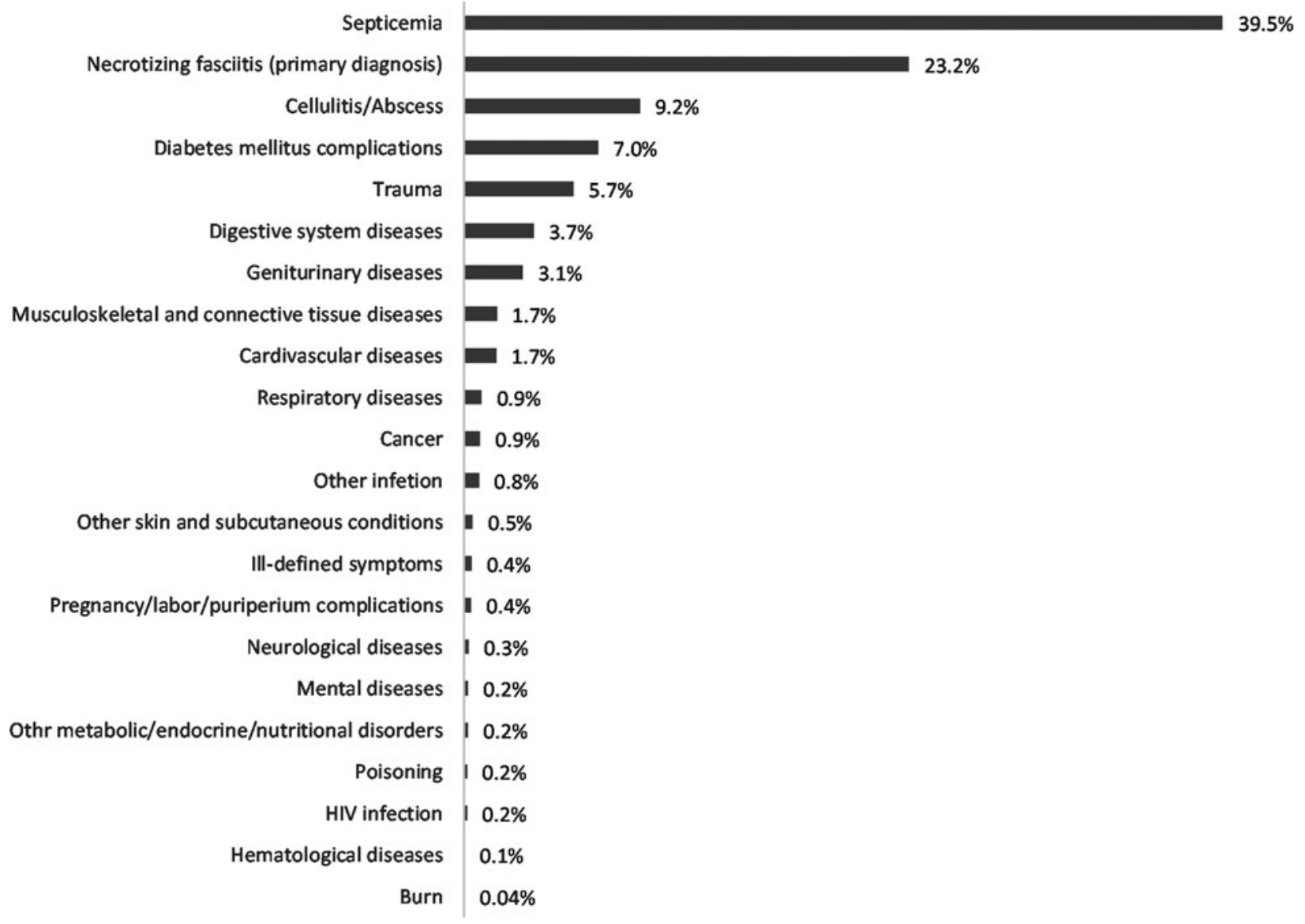

FIG. 1. Principal diagnosis of admission in patients presented emergently either with necrotizing fasciitis (NF) as the primary diagnosis or a secondary diagnosis. 
checked for completeness of data; records with missing values for the study parameters were excluded.

Comparing the presentation and outcomes of patients with diabetes with those without diabetes the following factors were considered: age: $<18,18-40,>40$ to $<60, \geq 60$ years; gender: male, female; obesity; current tobacco use, ICD-9 code: 305.1; history of alcohol abuse; history of drug abuse; trauma admission; development of septicemia; development of disseminated intravascular coagulopathy, ICD-9: 286.6; development of septic shock, ICD-9: 785.52.; development of cardiovascular, pulmonary, and renal complications during admission, ICD-9 codes adopted from previous study [9]; surgical intervention other than amputation; amputation, ICD-9 codes: 84.01-09, 84.10-19; utilization of hyperbaric oxygen therapy (HBOT), ICD-9: 939.5; utilization of hemodialysis, ICD-9: 399.5; received blood and blood component transfusion, ICD-9: 990.4, 990.5, 990.6, V58.2; received intravenous immunoglobulin (IVIG) therapy, ICD-9 code: 991.4 ; length of hospital stay in days, the total length of hospital stay of the first admission and re-admission if occurred; and cost of health services (the database includes hospital charges associated with each admission as well as cost-to-charge ratio determined for each hospital that allows conversion of charges values to cost values, all cost values were adjusted for inflation rate to reflect 2017 U.S dollar value using Bureau of Labor Statistics inflation calculator) $[7,10]$.

Factors that were assessed for their association with mortality, in addition to the factors in the previous paragraph, include a history of: complications from diabetes; chronic lung diseases; congestive heart failure; hypertension; peripheral vascular diseases; paralysis; rheumatoid arthritis/collagen vascular diseases; chronic liver diseases; chronic renal failure; malignancy without metastasis; malignancy with metastasis; and human immunodeficiency virus (HIV) infection.

Characteristics of patients who did not undergo surgical intervention were investigated. Factors examined included: age: $<65$, $\geq 65$ years; gender: male, female; Charlson comorbidity index score: $0-1,2-3, \geq 4$ [11]; trauma admission; development of septicemia; and insurance type: private, Medicare, Medicaid, self-pay.

Statistical analysis used weighted data reflecting a national estimate in calculating percentages and odds ratios. The records' weights are available in the NRD and calculated based on the stratification variables that were used in sampling methodology [7].

Statistical methods used in the analysis included $\chi^{2}$ tests to examine the association between each of the independent factors and the outcomes of interest. Factors that demonstrated association with the outcomes were considered possible confounders and were included in multivariable logistic regression models. Multivariable logistic regression models were used to calculate the odds ratio (OR) and 95\% confidence interval (CI). Linear regression model was used to compare means of length of hospital stay and cost of health services. Significance level was set as $(\alpha=0.05)$. All data analyses were performed using SAS 9.4 for Windows (SAS Institute Inc., Cary, NC).

\section{Results}

A total of 4,178 patients were identified who were admitted emergently with NF in the United States between 2010 and
2014 (Table 1). Septicemia was the most common diagnosis at presentation $(39.5 \%)$. Necrotizing fasciitis was a primary admission diagnosis in $23.3 \%$ of the sample. Trauma was the main presentation in $5.7 \%$ of the patients, whereas $9.2 \%$ initially were diagnosed as cellulitis or abscess cases (Fig. 1). The average age of the study population was $53.5 \pm 0.3$ years. Necrotizing fasciitis was statistically equally represented in both genders $(\mathrm{p}=0.08)$. Almost half of the patients $(\mathrm{n}=2,061$, $48.9 \%$ ) had a history of diabetes mellitus. Overall mortality risk was $12.6 \%(95 \% \mathrm{CI}=11.5-13.7 \%)$. There was no annual change in the risk of mortality throughout the study period (Fig. 2). Compared with patients who did not have diabetes, patients with diabetes who developed NF were more likely to be older than 40 years, obese, a non-smoker, and with no history of alcohol or drug abuse $(\mathrm{p}<0.001$ each). Patients with diabetes were less likely to present with trauma and septicemia $(\mathrm{p}<0.001$ each) and less likely to develop disseminated intravascular coagulopathy and septic shock $(\mathrm{p}<0.001$ each). Amputation risk was higher in patients with diabetes $(18.1 \%$ vs. $9.3 \%, \mathrm{p}<0.001)$. Mortality risk in patients with diabetes was substantially lower in the multivariable logistic regression model (8.5\% vs. $16.5 \%$, OR: 0.44 , $95 \% \mathrm{CI}=[0.34,0.56], \mathrm{p}<0.001)$, the model controlled for factors that demonstrated significant association with mortality in the univariable analysis, those factors are: age, gender, obesity, history of congestive health failure, history of peripheral vascular diseases, history of chronic liver diseases, history of chronic renal failure, history of nonmetastatic and metastatic malignancies, trauma admission, septicemia, septic shock, disseminated intravascular coagulopathy, undergoing surgical intervention, whether cardiovascular, pulmonary, and renal complications reported during admission; and whether hemodialysis and blood transfusion were performed during admission.

Considering patients without diabetes separately, factors that demonstrated association with mortality in the univariable analysis are shown in Table 2 . Those factors were included in the multivariable analysis that demonstrated the following factors to be with a higher risk of mortality in patients who do not have diabetes (Table 3 ): age $\geq 40$ years; history of congestive heart failure; history of peripheral vascular diseases; history of chronic liver diseases; history of malignancy without metastasis; septicemia; disseminated intravascular coagulopathy; septic shock; pulmonary complications during admission; acute renal failure during admission; not undergoing surgery with or without amputation; and receiving hemodialysis.

Univariable and multivariable analyses of risk factors of mortality in patients with diabetes are shown in Tables 4 and 5, respectively. Factors that retained substantial association with mortality risk in patients with diabetes included: age $\geq 60$ years; history of chronic liver diseases; history of chronic renal failure; disseminated intravascular coagulopathy; septic shock; pulmonary complications during admission; acute renal failure during admission; and not undergoing surgery.

It should be noted that in both groups no mortality was reported among patients who were $<18$ years, received HBOT, or received IVIG. For this reason, those factors were not assessed for their association with mortality in the univariable analysis.

Patients who did not undergo surgery were more likely to be $>65$ years, have multiple comorbidities, and with 
Table 1. Characteristics of Patients Admitted Emergently with Necrotizing Fascittis in Relation to Diabetes Mellitus, 2010-2014

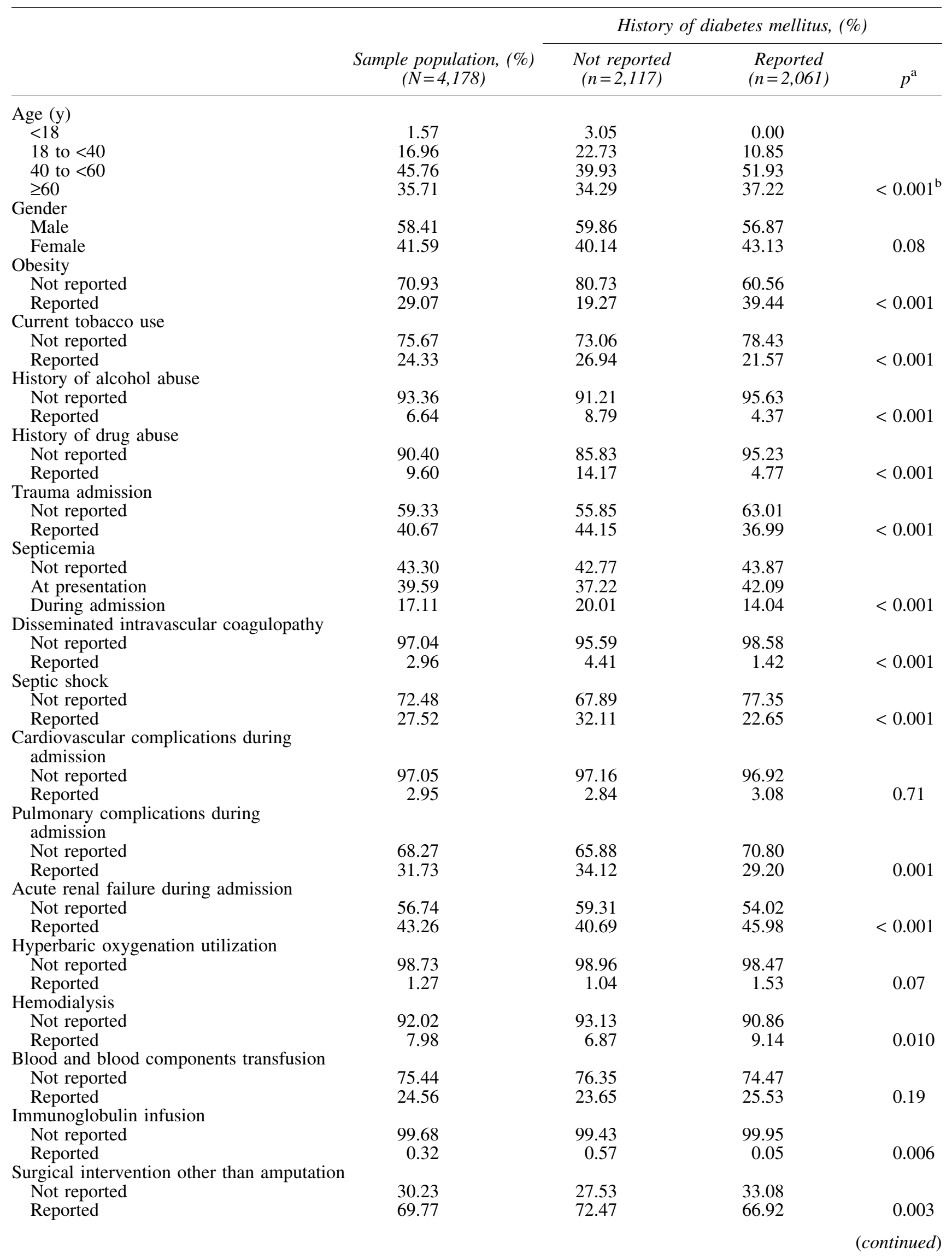


TABle 1. (CONTINUED)

\begin{tabular}{|c|c|c|c|c|}
\hline & \multirow[b]{2}{*}{$\begin{array}{c}\text { Sample population, }(\%) \\
(N=4,178)\end{array}$} & \multicolumn{3}{|c|}{ History of diabetes mellitus, (\%) } \\
\hline & & $\begin{array}{l}\text { Not reported } \\
\quad(n=2,117)\end{array}$ & $\begin{array}{l}\text { Reported } \\
(n=2,061)\end{array}$ & $p^{\mathrm{a}}$ \\
\hline \multicolumn{5}{|l|}{ Amputation } \\
\hline Not reported & 86.43 & 90.74 & 81.87 & \\
\hline Reported & 13.57 & 9.26 & 18.13 & $<0.001$ \\
\hline \multicolumn{5}{|l|}{ Thirty-day re-admission } \\
\hline Not reported & 87.68 & 88.72 & 86.59 & \\
\hline Reported & 12.32 & 11.28 & 13.41 & 0.06 \\
\hline \multicolumn{5}{|l|}{$\begin{array}{l}\text { In-hospital death within } 30 \mathrm{~d} \text { of initial } \\
\text { admission }\end{array}$} \\
\hline Not reported & 87.38 & 83.47 & 91.51 & \\
\hline Reported & 12.62 & 16.53 & 8.49 & $<0.001$ \\
\hline $\begin{array}{l}\text { Length of total hospital stay per case, } \\
\text { day, mean (SEM) }\end{array}$ & $17.99(0.32)$ & $17.57(0.43)$ & $18.44(0.43)$ & 0.17 \\
\hline $\begin{array}{l}\text { Cost of total health-services per case, } \\
\text { U.S.\$, mean (SEM) }\end{array}$ & $50,523.00(1,218.76)$ & $51,604.00(1,521.03$ & 49,377.00 (1,598.90) & 0.005 \\
\hline
\end{tabular}

Medicare insurance $(p<0.05$ each; Table 6$)$. They also were less likely to have been admitted because of trauma or have developed septicemia $(\mathrm{p}<0.001$ each).

\section{Discussion}

This study provides an overall picture of NF and associated outcomes in the United States by utilizing the NRD for the years 2010-2014. The database is unique because it provides a large nationally representative sample of a relatively rare condition. The study identified 4,178 cases of NF, with an overall mortality risk of $12.6 \%(95 \% \mathrm{CI}=11.5-13.7 \%)$. In a review of 67 studies published between 1980 and 2008, the author observed the pooled mortality risk was $23.5 \%$ with a slight annual downward trend [4]. However, those studies included heterogeneous populations with small sample sizes (range, 7-198 cases), pooling the mortality risk as opposed to more advanced statistical methods that would control for variations in sampled populations that could result in a misleading information. The large sample of this study and the application of weighted analysis are likely to have produced a more reliable estimate of mortality risk in the United States.

The mortality risk among patients without diabetes was $16.5 \%$, whereas the mortality risk among patients with diabetes was substantially lower, $8.5 \%$. Diabetes mellitus is a common comorbidity in patients who presented with NF, the prevalence of diabetes has been reported to be between $44.5 \%$ and $72.3 \%$ [2]. The association of diabetes with NF is believed to be related to poor capacity of wound healing and increased susceptibility of infection in patients with diabetes [2]. The microbiologic profile of NF in patients with diabetes has been reported to be different from that of patients who do not have diabetes [2]. Patients with diabetes are more susceptible to NF caused by polymicrobial infection [2]. For those reasons, we decided to analyze patients with diabetes separately from patients without diabetes.

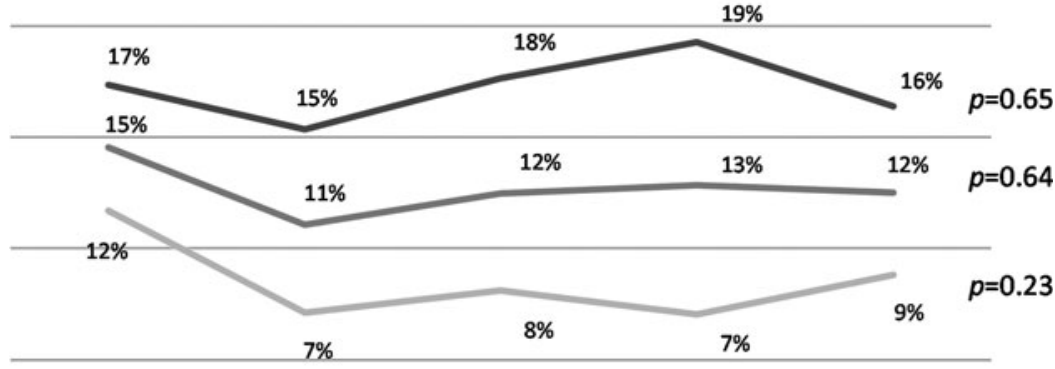

\begin{tabular}{ccccc}
\hline 2010 & 2011 & 2012 & 2013 & 2014 \\
& & History of diabetes mellitus & & No history of diabetes mellitus
\end{tabular}

FIG. 2. Annual mortality risk in a study population of patients admitted emergently with necrotizing fasciitis (NF). 
Table 2. Characteristics of Adult Patients without a History of Diabetes Mellitus Admitted Emergently With Necrotizing Fascittis in Relation to Mortality Risk, 2010-2014

\begin{tabular}{|c|c|c|c|c|}
\hline & \multirow[b]{2}{*}{$\begin{array}{l}\text { Sample population, }(\%) \\
(N=2,117)\end{array}$} & \multicolumn{3}{|c|}{$\begin{array}{l}\text { In-hospital death within } 30 \mathrm{~d} \\
\text { of initial admission, (\%) }\end{array}$} \\
\hline & & $\begin{array}{l}\text { Not reported } \\
(n=1,760)\end{array}$ & $\begin{array}{l}\text { Reported } \\
(n=357)\end{array}$ & $p^{\mathrm{a}}$ \\
\hline \multicolumn{5}{|l|}{ Age $(y)$} \\
\hline 18 to $<40$ & 23.44 & 26.96 & 6.36 & \\
\hline 40 to $<60$ & 41.19 & 42.47 & 34.96 & \\
\hline$\geq 60$ & 35.37 & 30.57 & 58.68 & $<0.001$ \\
\hline \multicolumn{5}{|l|}{ Gender } \\
\hline Male & 59.75 & 60.90 & 54.20 & \\
\hline Female & 40.25 & 39.10 & 45.80 & 0.017 \\
\hline \multicolumn{5}{|l|}{ Obesity } \\
\hline Not reported & 80.38 & 80.03 & 82.08 & \\
\hline Reported & 19.62 & 19.97 & 17.92 & 0.42 \\
\hline \multicolumn{5}{|c|}{ Current tobacco use } \\
\hline Not reported & 72.22 & 69.73 & 84.32 & \\
\hline Reported & 27.78 & 30.27 & 15.68 & $<0.001$ \\
\hline \multicolumn{5}{|c|}{ History of alcohol abuse } \\
\hline Not reported & 90.94 & 91.03 & 90.50 & \\
\hline Reported & 9.06 & 8.97 & 9.50 & 0.80 \\
\hline \multicolumn{5}{|c|}{ History of drug abuse } \\
\hline Not reported & 85.39 & 84.76 & 88.42 & \\
\hline Reported & 14.61 & 15.24 & 11.58 & 0.06 \\
\hline \multicolumn{5}{|c|}{ History of chronic lung diseases } \\
\hline Not reported & 84.93 & 85.23 & 83.50 & \\
\hline Reported & 15.07 & 14.77 & 16.50 & 0.48 \\
\hline \multicolumn{5}{|c|}{ History of congestive heart failure } \\
\hline Not reported & 90.47 & 92.53 & 80.47 & \\
\hline Reported & 9.53 & 7.47 & 19.53 & $<0.001$ \\
\hline \multicolumn{5}{|c|}{ History of hypertension } \\
\hline Not reported & 60.50 & 60.91 & 58.53 & \\
\hline Reported & 39.50 & 39.09 & 41.47 & 0.37 \\
\hline \multicolumn{5}{|c|}{ History of peripheral vascular diseases } \\
\hline Not reported & 94.10 & 95.30 & 88.27 & \\
\hline Reported & 5.90 & 4.70 & 11.73 & $<0.001$ \\
\hline \multicolumn{5}{|c|}{ History of paralysis } \\
\hline Not reported & 96.56 & 96.53 & 96.68 & \\
\hline Reported & 3.44 & 3.47 & 3.32 & 0.88 \\
\hline \multicolumn{5}{|c|}{$\begin{array}{l}\text { History of rheumatoid arthritis/collagen } \\
\text { vascular diseases }\end{array}$} \\
\hline Not reported & 96.75 & 97.12 & 94.95 & \\
\hline Reported & 3.25 & 2.88 & 5.05 & 0.07 \\
\hline \multicolumn{5}{|c|}{ History of chronic liver diseases } \\
\hline Not reported & 92.99 & 94.61 & 85.10 & \\
\hline Reported & 7.01 & 5.39 & 14.90 & $<0.001$ \\
\hline \multicolumn{5}{|c|}{ History of chronic renal failure } \\
\hline Not reported & 88.35 & 89.88 & 80.92 & \\
\hline Reported & 11.65 & 10.12 & 19.08 & $<0.001$ \\
\hline \multicolumn{5}{|c|}{ History of malignancy without metastasis } \\
\hline Not reported & 94.91 & 96.30 & 88.15 & \\
\hline Reported & 5.09 & 3.70 & 11.85 & $<0.001$ \\
\hline \multicolumn{5}{|c|}{ History of malignancy with metastasis } \\
\hline Not reported & 97.65 & 97.75 & 97.16 & \\
\hline Reported & 2.36 & 2.25 & 2.84 & 0.53 \\
\hline History of HIV i & & & & \\
\hline Not reported & 99.81 & 99.83 & 99.71 & \\
\hline Reported & 0.19 & 0.17 & 0.29 & 0.65 \\
\hline Trauma admissio & & & & \\
\hline Not reported & 55.83 & 57.90 & 45.77 & \\
\hline Reported & 44.17 & 42.10 & 54.23 & $<0.001$ \\
\hline
\end{tabular}


TABle 2. (CONTINUED)

\begin{tabular}{|c|c|c|c|c|}
\hline & \multirow[b]{2}{*}{$\begin{array}{c}\text { Sample population, }(\%) \\
(N=2,117)\end{array}$} & \multicolumn{3}{|c|}{$\begin{array}{l}\text { In-hospital death within } 30 d \\
\text { of initial admission, (\%) }\end{array}$} \\
\hline & & $\begin{array}{l}\text { Not reported } \\
\quad(n=1,760)\end{array}$ & $\begin{array}{l}\text { Reported } \\
(n=357)\end{array}$ & $p^{\mathrm{a}}$ \\
\hline \multicolumn{5}{|l|}{ Septicemia } \\
\hline No reported & 41.79 & 49.02 & 6.60 & \\
\hline At presentation & 38.18 & 32.29 & 66.80 & \\
\hline During admission & 20.03 & 18.68 & 26.59 & $<0.001$ \\
\hline \multicolumn{5}{|c|}{ Disseminated intravascular coagulopathy } \\
\hline Not reported & 95.45 & 98.13 & 82.45 & \\
\hline Reported & 4.55 & 1.87 & 17.55 & $<0.001$ \\
\hline \multicolumn{5}{|l|}{ Septic shock } \\
\hline Not reported & 67.19 & 76.32 & 22.80 & \\
\hline Reported & 32.81 & 23.68 & 77.20 & $<0.001$ \\
\hline \multicolumn{5}{|c|}{ Cardiovascular complications during admission } \\
\hline Not reported & 97.08 & 97.86 & 93.24 & \\
\hline Reported & 2.92 & 2.14 & 6.76 & $<0.001$ \\
\hline \multicolumn{5}{|c|}{ Pulmonary complications during admission } \\
\hline Not reported & 65.23 & 73.89 & 23.11 & \\
\hline Reported & 34.77 & 26.11 & 76.89 & $<0.001$ \\
\hline \multicolumn{5}{|c|}{ Acute renal failure during admission } \\
\hline Not reported & 58.03 & 65.21 & 23.11 & \\
\hline Reported & 41.97 & 34.79 & 76.89 & $<0.001$ \\
\hline \multicolumn{5}{|c|}{ Surgical intervention other than amputation } \\
\hline Not reported & 28.03 & 25.49 & 40.35 & \\
\hline Reported & 71.98 & 74.51 & 59.65 & $<0.001$ \\
\hline \multicolumn{5}{|l|}{ Amputation } \\
\hline Not reported & 90.45 & 91.55 & 85.07 & \\
\hline Reported & 9.55 & 8.45 & 14.93 & $<0.001$ \\
\hline \multicolumn{5}{|c|}{ Hyperbaric oxygenation utilization } \\
\hline Not reported & 99.08 & 98.89 & 100.00 & \\
\hline Reported & 0.92 & 1.11 & 0.00 & $\mathrm{NA}^{\mathrm{c}}$ \\
\hline \multicolumn{5}{|l|}{ Hemodialysis } \\
\hline Not reported & 92.91 & 95.80 & 78.87 & \\
\hline Reported & 7.09 & 4.20 & 21.13 & $<0.001$ \\
\hline \multicolumn{5}{|c|}{ Blood and blood components transfusion } \\
\hline Not reported & 75.70 & 78.91 & 60.06 & \\
\hline Reported & 24.30 & 21.09 & 39.94 & $<0.001$ \\
\hline \multicolumn{5}{|c|}{ Immunoglobulin infusion } \\
\hline Not reported & 99.41 & 99.29 & 100.00 & \\
\hline Reported & 0.59 & 0.71 & 0.00 & $\mathrm{NA}^{\mathrm{c}}$ \\
\hline
\end{tabular}

In a retrospective study from Taiwan by Cheng et al. [2] that used similar ICD-9 code to identify cases and reported 165 patients with NF, $51 \%$ had diabetes mellitus. Cheng et al. [2] reported no statistically significant difference in mortality between patients with and without diabetes, however, similar to this study patients with diabetes had a higher risk of undergoing amputation. Cheng et al. [2] also examined factors associated with mortality in patients with and without diabetes. Despite the multiple risk factors investigated, factors that were associated with a higher risk of mortality in patients with diabetes only included dyspnea at presentation and septicemia, whereas in patients without diabetes the risk factors identified were the functional status of the patient, pus at infection site, and systemic inflammatory response syndrome (SIRS) [2]. It is likely that the small sample size ren- dered the study underpowered to detect substantial differences in mortality associated with the examined factors [2].

There are conflicting results in the literature regarding the association of diabetes and mortality risk. Some studies failed to identify association with diabetes whereas others reported a negative prognosis $[12,13]$. The main limitation of all previous studies is the small sample size that rendered them underpowered to detect meaningful association and left room for random error. In a meta-analysis by Turner et al. [14] that examined the risk of mortality in patients who developed invasive fungal sinusitis, conflicting results regarding the association of diabetes with mortality risk were also found. Nonetheless, the final outcome of the meta-analysis demonstrated diabetes to be a good prognosis factor [14]. Although this is not well understood, it is believed that patients with 
Table 3. Factors Associated with Mortality in Adult Patients without a History of Diabetes Mellitus Admitted Emergently with Necrotizing Fasciitis

\begin{tabular}{|c|c|c|c|c|}
\hline & $\begin{array}{l}\text { In-hospital death within } 30 d \\
\text { of initial admission, (\%) }\end{array}$ & $O R^{\mathrm{a}}$ & $95 \% C I$ & $p$ \\
\hline \multicolumn{5}{|l|}{ Age $(y)$} \\
\hline 18 to $<40$ & 4.62 & Reference & & \\
\hline 40 to $<60$ & 14.47 & 2.10 & $1.30,3.38$ & 0.003 \\
\hline$\geq 60$ & 28.29 & 3.90 & $2.37,6.41$ & $<0.001$ \\
\hline \multicolumn{5}{|l|}{ Gender } \\
\hline Male & 15.46 & Reference & & \\
\hline Female & 19.40 & 1.11 & $0.82,1.50$ & 0.50 \\
\hline \multicolumn{5}{|l|}{ Current tobacco use } \\
\hline Not reported & 19.91 & Reference & & \\
\hline Reported & 9.62 & 0.73 & $0.50,1.06$ & 0.10 \\
\hline \multicolumn{5}{|c|}{ History of congestive heart failure } \\
\hline Not reported & 15.16 & Reference & & \\
\hline Reported & 34.96 & 1.53 & $1.02,2.30$ & 0.042 \\
\hline \multicolumn{5}{|c|}{ History of peripheral vascular diseases } \\
\hline Not reported & 15.99 & Reference & & \\
\hline Reported & 33.91 & 2.06 & $1.20,3.53$ & 0.009 \\
\hline \multicolumn{5}{|c|}{ History of chronic liver diseases } \\
\hline Not reported & 14.51 & Reference & & \\
\hline Reported & 33.59 & 2.35 & $1.45,3.83$ & $<0.001$ \\
\hline \multicolumn{5}{|c|}{ History of chronic renal failure } \\
\hline Not reported & 15.60 & Reference & & \\
\hline Reported & 36.24 & 1.17 & $0.76,1.79$ & 0.48 \\
\hline \multicolumn{5}{|c|}{ History of malignancy without metastasis } \\
\hline Not reported & 15.84 & Reference & & \\
\hline Reported & 39.70 & 1.88 & $1.09,3.22$ & 0.022 \\
\hline \multicolumn{5}{|l|}{ Trauma admission } \\
\hline Not reported & 13.98 & Reference & & \\
\hline Reported & 20.93 & 1.15 & $0.84,1.58$ & 0.37 \\
\hline \multicolumn{5}{|l|}{ Septicemia } \\
\hline No reported & 2.69 & 0.32 & $0.18,0.57$ & $<0.001$ \\
\hline At presentation & 29.83 & Reference & & \\
\hline During admission & 22.63 & 0.92 & $0.66,1.28$ & 0.60 \\
\hline \multicolumn{5}{|c|}{ Disseminated intravascular coagulopathy } \\
\hline Not reported & 14.73 & Reference & & \\
\hline Reported & 65.81 & 2.78 & $1.39,5.55$ & 0.004 \\
\hline \multicolumn{5}{|l|}{ Septic shock } \\
\hline Not reported & 5.78 & Reference & & \\
\hline Reported & 40.12 & 2.47 & $1.69,3.62$ & $<0.001$ \\
\hline \multicolumn{5}{|c|}{ Cardiovascular complications during admission } \\
\hline Not reported & 16.38 & Reference & & \\
\hline Reported & 39.38 & 1.20 & $0.61,2.36$ & 0.59 \\
\hline \multicolumn{5}{|c|}{ Pulmonary complications during admission } \\
\hline Not reported & 6.04 & Reference & & \\
\hline Reported & 37.71 & 3.39 & $2.32,4.95$ & $<0.001$ \\
\hline \multicolumn{5}{|c|}{ Acute renal failure during admission } \\
\hline Not reported & 6.79 & Reference & & \\
\hline Reported & 31.23 & 1.99 & $1.43,2.77$ & $<0.001$ \\
\hline \multicolumn{5}{|c|}{ Surgical intervention other than amputation } \\
\hline Not reported & 24.55 & Reference & & \\
\hline Reported & 14.13 & 0.37 & $0.26,0.54$ & $<0.001$ \\
\hline \multicolumn{5}{|l|}{ Amputation } \\
\hline Not reported & 16.04 & Reference & & \\
\hline Reported & 26.65 & 0.49 & $0.30,0.81$ & 0.005 \\
\hline Hemodialysis & & & & \\
\hline Not reported & 14.47 & Reference & & \\
\hline Reported & 50.81 & 1.68 & $1.06,2.67$ & 0.028 \\
\hline Blood and blood con & & & & \\
\hline Not reported & 13.53 & Reference & & \\
\hline Reported & 28.02 & 1.11 & $0.77,1.60$ & 0.59 \\
\hline
\end{tabular}

$\mathrm{OR}=$ adjusted odds ratio; $\mathrm{CI}=$ confidence interval.

${ }^{\mathrm{a}}$ Multivariate logistic regression model included all variables listed in the table. 
Table 4. Characteristics of Adult Patients with a History of Diabetes Mellitus Admitted Emergently with Necrotizing Fasciitis in Relation to Mortality Risk, 2010-2014

\begin{tabular}{|c|c|c|c|c|}
\hline & \multirow[b]{2}{*}{$\begin{array}{c}\text { Sample population, }(\%) \\
(N=2,061)\end{array}$} & \multicolumn{3}{|c|}{$\begin{array}{l}\text { In-hospital death within } 30 \text { days } \\
\text { of initial admission, }(\%)\end{array}$} \\
\hline & & $\begin{array}{l}\text { Not reported } \\
\quad(n=1,887)\end{array}$ & $\begin{array}{l}\text { Reported } \\
(n=174)\end{array}$ & $P^{\mathrm{a}}$ \\
\hline \multicolumn{5}{|l|}{ Age (yr.) } \\
\hline 18 to $<40$ & 10.85 & 11.64 & 2.26 & \\
\hline 40 to $<60$ & 51.93 & 53.59 & 34.08 & \\
\hline$\geq 60$ & 37.22 & 34.77 & 63.66 & $<0.001$ \\
\hline \multicolumn{5}{|l|}{ Gender } \\
\hline Male & 56.87 & 57.48 & 50.33 & \\
\hline Female & 43.13 & 42.52 & 49.67 & 0.09 \\
\hline \multicolumn{5}{|l|}{ Obesity } \\
\hline Not reported & 60.56 & 60.53 & 60.89 & \\
\hline Reported & 39.44 & 39.47 & 39.11 & 0.92 \\
\hline \multicolumn{5}{|c|}{ Current tobacco use } \\
\hline Not reported & 78.43 & 77.64 & 86.91 & \\
\hline Reported & 21.57 & 22.36 & 13.09 & 0.003 \\
\hline \multicolumn{5}{|c|}{ History of alcohol abuse } \\
\hline Not reported & 95.63 & 95.70 & 94.90 & \\
\hline Reported & 4.37 & 4.30 & 5.10 & 0.57 \\
\hline \multicolumn{5}{|c|}{ History of drug abuse } \\
\hline Not reported & 95.23 & 95.09 & 96.82 & \\
\hline Reported & 4.77 & 4.91 & 3.18 & 0.28 \\
\hline \multicolumn{5}{|c|}{ History of diabetes mellitus related complications } \\
\hline Not reported & 59.65 & 59.28 & 63.66 & \\
\hline Reported & 40.35 & 40.72 & 36.34 & 0.24 \\
\hline \multicolumn{5}{|c|}{ History of chronic lung diseases } \\
\hline Not reported & 84.02 & 84.12 & 82.88 & \\
\hline \multirow{2}{*}{\multicolumn{5}{|c|}{ History of congestive heart failure }} \\
\hline & & & & \\
\hline Not reported & 87.45 & 88.46 & 76.60 & \\
\hline Reported & 12.55 & 11.54 & 23.40 & $<0.001$ \\
\hline \multicolumn{5}{|c|}{ History of hypertension } \\
\hline Not reported & 32.97 & 33.35 & 28.84 & \\
\hline Reported & 67.03 & 66.65 & 71.16 & 0.20 \\
\hline \multicolumn{5}{|c|}{ History of peripheral vascular diseases } \\
\hline Not reported & 86.94 & 86.92 & 87.09 & \\
\hline Reported & 13.06 & 13.08 & 12.91 & 0.94 \\
\hline \multicolumn{5}{|c|}{ History of paralysis } \\
\hline Not reported & 98.23 & 98.22 & 98.33 & \\
\hline Reported & 1.77 & 1.78 & 1.67 & 0.93 \\
\hline \multicolumn{5}{|c|}{$\begin{array}{l}\text { History of rheumatoid arthritis/collagen vascular } \\
\text { diseases }\end{array}$} \\
\hline Not reported & 97.75 & 97.73 & 97.97 & \\
\hline Reported & 2.25 & 2.27 & 2.03 & 0.83 \\
\hline \multicolumn{5}{|c|}{ History of chronic liver diseases } \\
\hline Not reported & 94.93 & 96.20 & 81.19 & \\
\hline Reported & 5.07 & 3.80 & 18.81 & $<0.001$ \\
\hline \multicolumn{5}{|c|}{ History of chronic renal failure } \\
\hline Not reported & 77.64 & 79.33 & 59.42 & \\
\hline Reported & 22.36 & 20.67 & 40.58 & $<0.001$ \\
\hline \multicolumn{5}{|c|}{ History of malignancy without metastasis } \\
\hline Not reported & 97.28 & 97.51 & 94.81 & \\
\hline Reported & 2.72 & 2.49 & 5.19 & 0.07 \\
\hline History of malig & & & & \\
\hline Not reported & 99.29 & 99.44 & 97.72 & \\
\hline Reported & 0.71 & 0.56 & 2.28 & 0.008 \\
\hline History of HIV $\mathrm{i}$ & & & & \\
\hline Not reported & 99.70 & 99.77 & 98.99 & \\
\hline Reported & 0.30 & 0.23 & 1.01 & 0.06 \\
\hline
\end{tabular}


Table 4. (Continued)

\begin{tabular}{|c|c|c|c|c|}
\hline & \multirow[b]{2}{*}{$\begin{array}{c}\text { Sample population, }(\%) \\
(N=2,061)\end{array}$} & \multicolumn{3}{|c|}{$\begin{array}{l}\text { In-hospital death within } 30 \text { days } \\
\text { of initial admission, }(\%)\end{array}$} \\
\hline & & $\begin{array}{l}\text { Not reported } \\
(n=1,887)\end{array}$ & $\begin{array}{l}\text { Reported } \\
(n=174)\end{array}$ & $P^{\mathrm{a}}$ \\
\hline \multicolumn{5}{|l|}{ Trauma admission } \\
\hline Not reported & 63.01 & 64.08 & 51.49 & \\
\hline Reported & 36.99 & 35.92 & 48.51 & 0.001 \\
\hline \multicolumn{5}{|l|}{ Septicemia } \\
\hline No reported & 43.87 & 46.47 & 15.81 & \\
\hline At presentation & 42.09 & 40.09 & 63.70 & \\
\hline During admission & 14.04 & 13.44 & 20.48 & $<0.001$ \\
\hline \multicolumn{5}{|c|}{ Disseminated intravascular coagulopathy } \\
\hline Not reported & 98.58 & 99.13 & 92.66 & \\
\hline \multirow{2}{*}{\multicolumn{5}{|c|}{ Septic shock }} \\
\hline & & & & \\
\hline Not reported & 77.35 & 81.47 & 32.92 & \\
\hline Reported & 22.65 & 18.53 & 67.08 & $<0.001$ \\
\hline \multicolumn{5}{|c|}{ Cardiovascular complications during admission } \\
\hline Not reported & 96.92 & 97.18 & 94.08 & \\
\hline Reported & 3.08 & 2.82 & 5.92 & 0.035 \\
\hline \multicolumn{5}{|c|}{ Pulmonary complications during admission } \\
\hline Not reported & 70.80 & 74.68 & 28.97 & \\
\hline Reported & 29.20 & 25.32 & 71.03 & $<0.001$ \\
\hline \multicolumn{5}{|c|}{ Acute renal failure during admission } \\
\hline Not reported & 54.02 & 56.54 & 26.91 & \\
\hline Reported & 45.98 & 43.46 & 73.09 & $<0.001$ \\
\hline \multicolumn{5}{|c|}{ Surgical intervention other than amputation } \\
\hline Not reported & 15.09 & 13.71 & 29.90 & \\
\hline Reported & 84.91 & 86.29 & 70.10 & $<0.001$ \\
\hline \multicolumn{5}{|l|}{ Amputation } \\
\hline Not reported & 90.45 & 91.55 & 85.07 & \\
\hline Reported & 9.55 & 8.45 & 14.93 & $<0.001$ \\
\hline \multicolumn{5}{|c|}{ Hyperbaric oxygenation utilization } \\
\hline Not reported & 99.08 & 98.33 & 100.00 & \\
\hline Reported & 0.92 & 1.67 & 0.00 & $\mathrm{NA}^{\mathrm{c}}$ \\
\hline \multicolumn{5}{|l|}{ Hemodialysis } \\
\hline Not reported & 90.86 & 92.34 & 74.85 & \\
\hline Reported & 9.14 & 7.66 & 25.15 & $<0.001$ \\
\hline \multicolumn{5}{|c|}{ Blood and blood components transfusion } \\
\hline Not reported & 74.47 & 75.31 & 65.44 & \\
\hline Reported & 25.53 & 24.69 & 34.56 & 0.003 \\
\hline \multicolumn{5}{|c|}{ Immunoglobulin infusion } \\
\hline Not reported & 99.95 & 99.94 & 100.00 & \\
\hline Reported & 0.05 & 0.06 & 0.00 & $\mathrm{NA}^{\mathrm{c}}$ \\
\hline
\end{tabular}

diabetes are liable to develop infection. However, by controlling blood glucose levels, the infection is less likely to progress, thus blood glucose is hypothesized to be a modifiable risk factor that would improve survival; this is still to be proven [14]. Notably, the study demonstrated that septicemia was a risk factor of mortality only in patients who did not have diabetes, whereas septic shock was a risk factor of mortality in both groups. This might indicate that patients with diabetes are more likely to recover from septicemia than those without diabetes and it is probably for this reason that patients with diabetes had a lower mortality risk.

Patients who had chronic liver disease were at a higher risk of mortality in both studies groups. In a study by Liu et al.
[15] that included 118 patients with liver cirrhosis who were admitted with soft tissue infection, 22 (18.6\%) patients had proven NF, 8 (36.3\%) of whom died. Infection in patients with chronic liver disease triggers excessive proinflammatory cytokines response, which in addition to pre-existing hemodynamic derangement, has been attributed to poor infection consequences in this population. ${ }^{16}$

Early identification of NF is a major determinant of survival. ${ }^{17}$ However, studies have demonstrated NF is often misdiagnosed as cellulitis or abscess approximately $50 \%$ of the time, which resulted in a delayed intervention $[4,8,15,17,18]$. In this study, $9.2 \%$ of patients were admitted initially as cases of cellulitis or abscess. However, it is unclear from 
Table 5. Factors Associated with the Risk of Mortality in Adult Patients with a History of Diabetes Mellitus Admitted Emergently with Necrotizing Fasciitis

\begin{tabular}{|c|c|c|c|c|}
\hline & $\begin{array}{l}\text { In-hospital death within } 30 \text { days } \\
\text { of initial admission, (\%) }\end{array}$ & $O R^{\mathrm{a}}$ & $95 \% C I$ & $p$ \\
\hline \multicolumn{5}{|l|}{ Age $(y)$} \\
\hline 18 to $<40$ & 1.77 & Reference & & \\
\hline 40 to $<60$ & 5.57 & 2.99 & $0.95,9.43$ & 0.06 \\
\hline$\geq 60$ & 14.52 & 6.01 & $1.87,19.34$ & 0.003 \\
\hline \multicolumn{5}{|l|}{ Current tobacco use } \\
\hline Not reported & 9.41 & Reference & & \\
\hline Reported & 5.15 & 0.84 & $0.49, \quad 1.42$ & 0.50 \\
\hline \multicolumn{5}{|c|}{ History of congestive heart failure } \\
\hline Not reported & 7.43 & Reference & & \\
\hline Reported & 15.83 & 1.11 & $0.71, \quad 1.75$ & 0.65 \\
\hline \multicolumn{5}{|c|}{ History of chronic liver diseases } \\
\hline Not reported & 7.26 & Reference & & \\
\hline Reported & 31.48 & 6.67 & $4.29,10.38$ & $<0.001$ \\
\hline \multicolumn{5}{|c|}{ History of chronic renal failure } \\
\hline Not reported & 6.50 & Reference & & \\
\hline Reported & 15.41 & 1.84 & $1.24, \quad 2.73$ & 0.003 \\
\hline \multicolumn{5}{|c|}{ History of malignancy with metastasis } \\
\hline Not reported & 8.35 & Reference & & \\
\hline Reported & 27.36 & 4.80 & $0.98,23.53$ & 0.05 \\
\hline \multicolumn{5}{|l|}{ Trauma admission } \\
\hline Not reported & 6.94 & Reference & & \\
\hline Reported & 11.13 & 1.02 & $0.70, \quad 1.49$ & 0.91 \\
\hline \multicolumn{5}{|l|}{ Septicemia } \\
\hline No reported & 3.06 & 0.59 & $0.34, \quad 1.02$ & 0.06 \\
\hline At presentation & 12.85 & Reference & & \\
\hline During admission & 12.38 & 0.66 & $0.41, \quad 1.07$ & 0.09 \\
\hline \multicolumn{5}{|c|}{ Disseminated intravascular coagulopathy } \\
\hline Not reported & 7.98 & Reference & & \\
\hline Reported & 43.82 & 3.43 & $1.40,8.41$ & 0.007 \\
\hline \multicolumn{5}{|l|}{ Septic shock } \\
\hline Not reported & 3.61 & Reference & & \\
\hline Reported & 25.13 & 3.96 & $2.42, \quad 6.48$ & $<0.001$ \\
\hline \multicolumn{5}{|c|}{ Cardiovascular complications during admission } \\
\hline Not reported & 8.24 & Reference & & \\
\hline Reported & 16.32 & 1.14 & $0.53, \quad 2.48$ & 0.73 \\
\hline \multicolumn{5}{|c|}{ Pulmonary complications during admission } \\
\hline Not reported & 3.47 & Reference & & \\
\hline Reported & 20.65 & 2.74 & $1.77, \quad 4.24$ & $<0.001$ \\
\hline \multicolumn{5}{|c|}{ Acute renal failure during admission } \\
\hline Not reported & 4.23 & Reference & & \\
\hline Reported & 13.49 & 1.52 & $1.03,2.26$ & 0.037 \\
\hline \multicolumn{5}{|c|}{ Surgical intervention other than amputation } \\
\hline Not reported & 16.82 & Reference & & \\
\hline Reported & 7.01 & 0.31 & $0.20, \quad 0.50$ & $<0.001$ \\
\hline \multicolumn{5}{|l|}{ Amputation } \\
\hline Not reported & 9.08 & Reference & & \\
\hline Reported & 5.80 & 0.74 & $0.45, \quad 1.24$ & 0.26 \\
\hline \multicolumn{5}{|l|}{ Hemodialysis } \\
\hline Not reported & 6.99 & Reference & & \\
\hline Reported & 23.35 & 1.34 & $0.82, \quad 2.20$ & 0.24 \\
\hline \multicolumn{5}{|c|}{ Blood and blood components transfusion } \\
\hline Not reported & 7.46 & Reference & & \\
\hline Reported & 11.49 & 0.98 & $0.66, \quad 1.47$ & 0.93 \\
\hline
\end{tabular}

$\mathrm{OR}=$ odds ratio; $\mathrm{CI}=$ confidence interval.

${ }^{a}$ Multivariate logistic regression model included all variables listed in the table.

data whether this was an initial misdiagnosis of NF or cellulitis that developed into NF during admission. Given the aggressive nature of NF, the subpopulation at high risk of mortality based on the risk factors identified here, especially those pertaining to comorbidities, should give a sign and raise a differential diagnosis of NF when encountering patient of this group presenting with soft tissue infection.

Surgical debridement and antibiotic agents are the mainstay treatment of NF $[1,4]$. 
Table 6. Characteristics of Patients with Necrotizing Fasciitis Who Were Less Likely TO UNDERGo SURGICAL INTERVENTION

\begin{tabular}{|c|c|c|c|c|}
\hline & Risk of not undergoing surgery, (\%) & $O R^{\mathrm{a}}$ & $95 \% C I$ & $P$ \\
\hline \multicolumn{5}{|l|}{ Age (yr) } \\
\hline$<65$ & 14.74 & Reference & & \\
\hline$\geq 65$ & 23.92 & 1.40 & $1.09,1.80$ & 0.009 \\
\hline \multicolumn{5}{|l|}{ Gender } \\
\hline Male & 16.63 & Reference & & \\
\hline Female & 17.32 & 1.01 & $0.84,1.21$ & 0.95 \\
\hline \multicolumn{5}{|c|}{ Charlson comorbidity index score } \\
\hline $0-1$ & 13.48 & Reference & & \\
\hline $2-3$ & 19.81 & 1.48 & $1.16,1.89$ & 0.002 \\
\hline$\geq 4$ & 31.55 & 2.42 & $1.77,3.31$ & $<0.001$ \\
\hline \multicolumn{5}{|c|}{ Trauma admission } \\
\hline Not reported & 19.91 & Reference & & \\
\hline Reported & 12.55 & 0.61 & $0.50,0.73$ & $<0.001$ \\
\hline \multicolumn{5}{|l|}{ Septicemia } \\
\hline Not reported & 20.37 & Reference & & \\
\hline Reported & 14.27 & 0.65 & $0.53,0.80$ & $<0.001$ \\
\hline \multicolumn{5}{|l|}{ Insurance type } \\
\hline Private & 14.11 & Reference & & \\
\hline Medicare & 22.61 & 1.37 & $1.08,1.74$ & 0.010 \\
\hline Medicaid & 15.29 & 1.08 & $0.83,1.41$ & 0.56 \\
\hline Self-pay & 12.51 & 0.90 & $0.64,1.26$ & 0.53 \\
\hline
\end{tabular}

${ }^{a}$ Multivariate logistic regression model included all variables listed in the table.

OR, adjusted odds ratio; CI, confidence interval.

Hyperbaric oxygen therapy has been proposed as adjunct therapy [19]. In this study the utilization of HBOT was reported in $1.3 \%$ of the sample. Hyperbaric oxygen therapy was not reported among patients who died, which prevented statistical evaluation of HBOT impact on mortality risk. There is a lack of evidence supporting the use of HBOT in patients with NF. In a retrospective study by Massey et al. [19] that included 80 patients with NF, $32(40 \%)$ patients received HBOT as part of their treatment. They reported no statistically significant difference in number of operations performed, amputations, and mortality risk comparing patients who received HBOT to those who did not. Massey et al. [19] calculated the statistical power in their study to be only approximately 0.25 to detect a $10 \%$ absolute reduction in mortality associated with HBOT. To have a statistical power of 0.8 , they would have needed an additional 261 patients.

Similar to HBOT, IVIG was used in a small proportion of patients $(0.3 \%)$ and with no reported use among patients who died. Intravenous immunoglobulin as a treatment of NF is still theoretical, partially supported by its efficacy in other type of infection [20]. In a randomized, blinded, placebocontrolled trial at Copenhagen University Hospital that included 100 patients with NF admitted to the intensive care unit, no apparent effects of adjuvant IVIG on self-reported physical functioning was observed at six months [20]. In another retrospective study by Kadri et al. [21] that involved 164 patients, reported adjunctive IVIG had no apparent impact on mortality or hospital length of stay compared with debridement and antibiotic agents alone.

The NRB does not provide information regarding the reasons behind not undergoing surgery in $16.9 \%$ of the study sample. However, those patients might not have been fit to undergo general anesthesia because statistically they were more likely to be $>65$ years and to have multiple comorbid- ities. Paradoxically, controlling for age and comorbidities, it appears that patients who had a less severe presentation-a non-traumatic presentation or without septicemia-were less likely to undergo surgery. It is alarming that septicemia was a factor to undergo surgery in patients who presented emergently with NF because development of septicemia was an independent risk factor of mortality; this might reflect a delay in diagnosis. Nevertheless, this was reported in a small proportion of the study population and the circumstances behind not undergoing surgery cannot be fully elucidated using this database, further investigation is warranted using a more detailed clinical data.

The study has multiple limitations. Causality cannot be established because the data were collected crosssectionally. The NRD is an administrative database that lacks clinical details such as culture and sensitivity reports, laboratory values, utilization of antibiotic agents, surgical details, number of procedures, severity of condition, and site of NF because the ICD-9 code used to identify cases lacks information regarding site; however, this ICD-9 code has been used previously by other studies that allowed for comparison with previous outcomes $[2,5,8]$. The lack of the above factors hinder elucidating the underlying factors behind the observed outcomes in the study. The study period is also relatively short to demonstrate meaningful trend analysis. Despite these limitations, the database provides a large sample size of a relatively rare condition. The data is suitable for assessment of overall national prevalence of NF and the associated burden in terms of mortality, length of hospital stay, and cost. The NRD includes a wide array of factors that were considered for their potential confounding effect. Additionally, the application of weighted analysis generates more accurate national estimates of the outcomes in the United States. 


\section{Conclusions}

To our knowledge, this is the largest study to examine the outcomes and risk factors of NF. Septicemia is present at the time of admission in $40 \%$ of patients. Mortality risk appears to be lower than reported previously by smaller scale studies and remains stable throughout the study period, however, it was higher in patients who did not have diabetes. This study identified multiple risk factors associated with mortality. A high index of suspicion should be practiced when soft tissue infection develops in patients with chronic comorbidities. Comorbidities observed to be associated with a higher risk of mortality included congestive heart failure, peripheral vascular diseases, chronic liver diseases, and malignancy. The mainstay treatment is surgery and antibiotic ageents; HBOT and IVIG are currently being investigated as adjunctive therapy. In this study both modules were used infrequently with no reported use among patients who died, which prevented statistical evaluation of their impact on survival. Future studies with larger sample size and more detailed clinical information are warranted as well as studies aimed at understanding the complex and changing microbiology profile of NF that would guide antimicrobial therapy.

\section{Funding Information}

Al-Qurayshi is supported by National Institutes of HealthInstitutional National Research Award: T32. None of the other authors have anything to disclose.

\section{Author Disclosure Statement}

All authors of this work declare no conflict of interest.

\section{References}

1. Madsen MB, Skrede S, Bruun T, et al. Necrotizing soft tissue infections-A multicentre, prospective observational study (INFECT): Protocol and statistical analysis plan. Acta Anaesthesiol Scand 2018;62:272-279.

2. Cheng NC, Tai HC, Chang SC, et al. Necrotizing fasciitis in patients with diabetes mellitus: Clinical characteristics and risk factors for mortality. BMC Infect Dis 2015;15:417.

3. Hua C, Sbidian E, Hemery F, et al. Prognostic factors in necrotizing soft-tissue infections (NSTI): A cohort study. J Am Acad Dermatol 2015;73:1006-1012.

4. May AK. Skin and soft tissue infections. Surg Clin North Am 2009;89(2):403-420, viii.

5. Ellis Simonsen SM, van Orman ER, Hatch BE, et al. Cellulitis incidence in a defined population. Epidemiol Infect 2006;134:293-299.

6. Elliott DC, Kufera JA, Myers RA. Necrotizing soft tissue infections. Risk factors for mortality and strategies for management. Ann Surg 1996;224:672-683.

7. Healthcare Cost and Utilization Project (HCUP). Overview of the nationwide readmissions database (NRD). www .hcup-us.ahrq.gov/nrdoverview.jsp. Updated 2017. (Last accessed June 18, 2018.)
8. Hsiao CT, Weng HH, Yuan YD, et al. Predictors of mortality in patients with NF. Am J Emerg Med 2008;26:170-175.

9. Al-Qurayshi Z, Robins R, Hauch A, et al. Association of surgeon volume with outcomes and cost savings following thyroidectomy: A national forecast. JAMA Otolaryngol Head Neck Surg 2016;142:32-39.

10. United States Department of Labor. Bureau of Labor Statistics. Databases, tables \& calculators by subject: Consumer price index. Updated 2016. www.bls.gov/data/ (Last accessed September 18, 2016).

11. Quan H, Sundararajan V, Halfon P, et al. Coding algorithms for defining comorbidities in ICD-9-CM and ICD-10 administrative data. Med Care 2005;43:1130-1139.

12. Wang JM, Lim HK. Necrotizing fasciitis: Eight-year experience and literature review. Braz J Infect Dis 2014;18: 137-143.

13. Chang CP, Hsiao CT, Lin CN, Fann WC. Risk factors for mortality in the late amputation of necrotizing fasciitis: A retrospective study. World J Emerg Surg 2018;13:45.

14. Turner JH, Soudry E, Nayak JV, Hwang PH. Survival outcomes in acute invasive fungal sinusitis: A systematic review and quantitative synthesis of published evidence. Laryngoscope 2013;123:1112-1118.

15. Liu BM, Chung $\mathrm{KJ}$, Chen $\mathrm{CH}$, et al. Risk factors for the outcome of cirrhotic patients with soft tissue infections. J Clin Gastroenterol 2008;42:312-316.

16. Bunchorntavakul C, Chamroonkul N, Chavalitdhamrong D. Bacterial infections in cirrhosis: A critical review and practical guidance. World J Hepatol 2016;8:307-321.

17. Wong $\mathrm{CH}$, Khin LW, Heng KS, et al. The LRINEC (laboratory risk indicator for NF) score: A tool for distinguishing NF from other soft tissue infections. Crit Care Med 2004;32:1535-1541.

18. Frazee BW, Fee C, Lynn J, et al. Community-acquired necrotizing soft tissue infections: A review of 122 cases presenting to a single emergency department over 12 years. J Emerg Med 2008;34:139-146.

19. Massey PR, Sakran JV, Mills AM, et al. Hyperbaric oxygen therapy in necrotizing soft tissue infections. J Surg Res 2012;177:146-151.

20. Madsen MB, Hjortrup PB, Hansen MB, et al. Immunoglobulin $\mathrm{G}$ for patients with necrotising soft tissue infection (INSTINCT): A randomised, blinded, placebo-controlled trial. Intensive Care Med 2017;43:1585-1593.

21. Kadri SS, Swihart BJ, Bonne SL, et al. Impact of intravenous immunoglobulin on survival in NF with vasopressordependent shock: A propensity score-matched analysis from 130 US hospitals. Clin Infect Dis 2017;64:877-885.

Address correspondence to: Dr. Emad Kandil

Tulane School of Medicine Department of Surgery

1430 Tulane Avenue, SL-22 New Orleans, LA 70112

USA

E-mail: ekandil@tulane.edu 